\title{
COVID-19-associated meningoencephalitis complicated with intracranial hemorrhage: a case report
}

\author{
Mohammad Al-olama ${ }^{1}$ (D) $\cdot$ Anas Rashid $^{1}$ • Debora Garozzo ${ }^{2}$ \\ Received: 7 May 2020 / Accepted: 10 May 2020 / Published online: 20 May 2020 \\ (C) Springer-Verlag GmbH Austria, part of Springer Nature 2020
}

\begin{abstract}
The coronavirus pandemic that started in December 2019 is mainly related to clinical pictures consistent with respiratory symptoms; nevertheless, reports about neurological complications have recently appeared in the medical literature. We describe a case of a 36-year-old coronavirus-positive patient that was admitted on emergency basis; his clinical presentation included neurological symptoms such as drowsiness and mild confusion. Imaging revealed findings consistent with meningoencephalitis complicated by intracerebral hematoma and subdural hematoma. The latter was surgically evacuated after it became chronic and evidence of coronavirus was found in the fluid. Our experience confirms that neurological complications might be a likely event in COVID-19. Although uncommon, the possible occurrence of meningoencephalitis should be kept in mind by physicians involved in the management of COVID-19 patients. Early recognition of brain involvement may provide better prognosis, preventing evolution into intracerebral hemorrhagic events.
\end{abstract}

Keywords COVID-19 $\cdot$ ICH $\cdot$ SDH $\cdot$ Meningoencephalitis $\cdot$ Encephalitis

\section{Introduction}

Coronavirus disease 2019 (COVID-19) started in December 2019, and about 3.8 million confirmed cases and more than 260,000 deaths have been reported worldwide until present date. Although the typical clinical picture is mainly related to the respiratory system and usually includes symptoms as fever, shortness of breath, and cough, there is ongoing evidence that other body systems might be affected. Neurological manifestations have also been reported [1, 2, 6, 7, 13]; a case of COVID-19-associated acute necrotizing hemorrhagic encephalopathy was recently published [9].

We describe a case of COVID-19-associated meningoencephalitis complicated with intracerebral hemorrhage and subdural hematoma.

This article is part of the Topical Collection on Infection

Mohammad Al-olama

dralolama@gmail.com

1 Rashid Hospital, Dubai Health Authority, Dubai, United Arab Emirates

2 Neurospinal Hospital, Dubai, United Arab Emirates

\section{Case report}

A 36-year-old male patient presented to one of the peripheral healthcare centers on April 15, 2020, with 2 days history of fever, headache, body pain, cough, diarrhea and vomiting. On physical examination, pharyngitis only was found. Blood tests showed normal full blood count. The patient was submitted to novel coronavirus RNA PCR swab that resulted negative. He was diagnosed as gastroenteritis and discharged.

On April 19, 2020, the patient visited the emergency department of a central hospital as he was still complaining of the same symptoms; additionally, he presented with drowsiness and appeared mildly confused. The patient denied head trauma or seizure.

On examination, Glasgow Coma Scale (GCS) scored 13/ 15 ; the patient was drowsy but arousable, and he showed mild confusion although he was still oriented to time and place. Pupils were isochoric (3-mm diameter) and reactive. Cranial nerves were normal. He presented no signs of trauma, no overt weakness, no nuchal rigidity (mild stiffness), or pain while moving the neck.

Blood tests (Table 1, 2, 3, and 4) showed high WBC count $12.910^{\wedge} 3 / \mathrm{uL}$; CRP was normal, procalcitonin was high $0.10 \mathrm{ng} / \mathrm{mL}$, and D-dimer was high $0.79 \mu \mathrm{g} / \mathrm{ml} \mathrm{FEU}$. Random glucose was high $165 \mathrm{mg} / \mathrm{d}$. 
Table 1 Coagulation profile

\begin{tabular}{lcc}
\hline Prothrombin time & $11-14 \mathrm{~s}$ & 12.8 \\
\hline Prothrombin time ratio & & 0.95 \\
INR & $0.8-1.1$ & 0.93 \\
PT Control & & 13.5 \\
APTT & $28-41 \mathrm{~s}$ & 30.9 \\
\hline
\end{tabular}

Table 2 Lever function test

\begin{tabular}{lll}
\hline Bilirubin (total) & $0-1.0 \mathrm{mg} / \mathrm{dL}$ & 0.3 \\
\hline Alkaline phosphatase & $40-129 \mathrm{U} / \mathrm{L}$ & 108 \\
SGPT(ALT) & $0-41 \mathrm{U} / \mathrm{L}$ & 196 high \\
Total protein & $6.6-8.7 \mathrm{~g} / \mathrm{dL}$ & 7.4 \\
Albumin & $3.4-4.8 \mathrm{~g} / \mathrm{dL}$ & 3.6 \\
Globulin & $2.8-3.4 \mathrm{~g} / \mathrm{dL}$ & 3.8 high \\
\hline
\end{tabular}

Table 3 G6PD

\begin{tabular}{llc}
\hline G-6PD screen & Normal & Normal \\
\hline G6PD quantitative & $146-376 \mathrm{u} / 10^{\wedge} 12 \mathrm{RBC}$ & 173 \\
\hline
\end{tabular}

Novel coronavirus RNA PCR swab was repeated and resulted positive.

Chest X-ray was performed and did not show any pathological findings.

Based on neurological examination, the patient was investigated with brain CT (Fig. 1). The study showed a right frontal intracerebral hematoma associated with subarachnoid hemorrhage in the ipsilateral sylvian fissure and frontal and temporal lobes; a thin, acute subdural hematoma was also evident. The hematoma appeared surrounded by edema and caused midline shift. The radiologist attributed the described findings to encephalitis, and viral etiology was suspected.

Diagnostic workup was completed with CT-angio on the same day (Fig. 2a and b). The investigation did not show any arteriovenous malformation or aneurysms, and it also ruled out the possibility of venous thrombosis. Bilateral supratentorial leptomeningeal increased enhancement was detected and further supported the diagnosis of COVID-19related meningoencephalitis (Fig. 3a and b).

The evidence of midline shift on the CT scans contraindicated a lumbar puncture to assess the presence of coronavirus in the CSF.

MRI could not be performed as in our facility it is not allowed for COVID-19 patients.

EEG was also ruled out to prevent further exposure with the COVID-19 patient and because CT and CTA were reckoned conclusive.
Table 4 Respiratory screening panel PCR nasopharynx

\begin{tabular}{|c|c|c|}
\hline & Ref range \& units & 2 days ago \\
\hline Influenza A PCR & Not detected (negative) & Not detected (negative) \\
\hline Influenza B PCR & Not detected (negative) & Not detected (negative) \\
\hline Para influenza 1 PCR & Not detected (negative) & Not detected (negative) \\
\hline Para influenza 2 PCR & Not detected (negative) & Not detected (negative) \\
\hline Para influenza 3 PCR & Not detected (negative) & Not detected (negative) \\
\hline Para influenza 4 PCR & Not detected (negative) & Not detected (negative) \\
\hline Bordetella pertussis PCR & Not detected (negative) & Not detected (negative) \\
\hline Mycoplasma pneumoniae PCR & Not detected (negative) & Not detected (negative) \\
\hline Enterovirus/rhinovirus PCR & Not detected (negative) & Not detected (negative) \\
\hline Influenza A subtype H1N1/2009 PCR & Not detected (negative) & Not detected (negative) \\
\hline Influenza A subtype H1 PCR & Not detected (negative) & Not detected (negative) \\
\hline Influenza A subtype H3 PCR & Not detected (negative) & Not detected (negative) \\
\hline Coronavirus 229E PCR & Not detected (negative) & Not detected (negative) \\
\hline \multicolumn{3}{|c|}{ Comment: This panel does not detect MERS coronavirus and 2019 novel coronavirus } \\
\hline Coronavirus HKU1 PCR & Not detected (negative) & Not detected (negative) \\
\hline \multicolumn{3}{|c|}{ Comment: This panel does not detect MERS coronavirus and 2019 novel coronavirus } \\
\hline Coronavirus NL63 PCR & Not detected (negative) & Not detected (negative) \\
\hline \multicolumn{3}{|c|}{ Comment: This panel does not detect MERS coronavirus and 2019 novel coronavirus } \\
\hline Coronavirus OC43 PCR & Not detected (negative) & Not detected (negative) \\
\hline \multicolumn{3}{|c|}{ Comment: This panel does not detect MERS coronavirus and 2019 novel coronavirus } \\
\hline Respiratory syncytial virus A + B PCR & Not detected (negative) & Not detected (negative) \\
\hline Human metapneumovirus A + B PCR & Not detected (negative) & Not detected (negative) \\
\hline Adenovirus PCR & Not detected (negative) & Not detected (negative) \\
\hline Chlamydia pneumoniae & Not detected (negative) & Not detected (negative) \\
\hline MERS coronavirus & Not detected (negative) & Not detected (negative) \\
\hline \multicolumn{3}{|c|}{ Comment: This panel does not detect 2019 novel coronavirus } \\
\hline Bordetella parapertussis & Not detected (negative) & Not detected (negative) \\
\hline
\end{tabular}




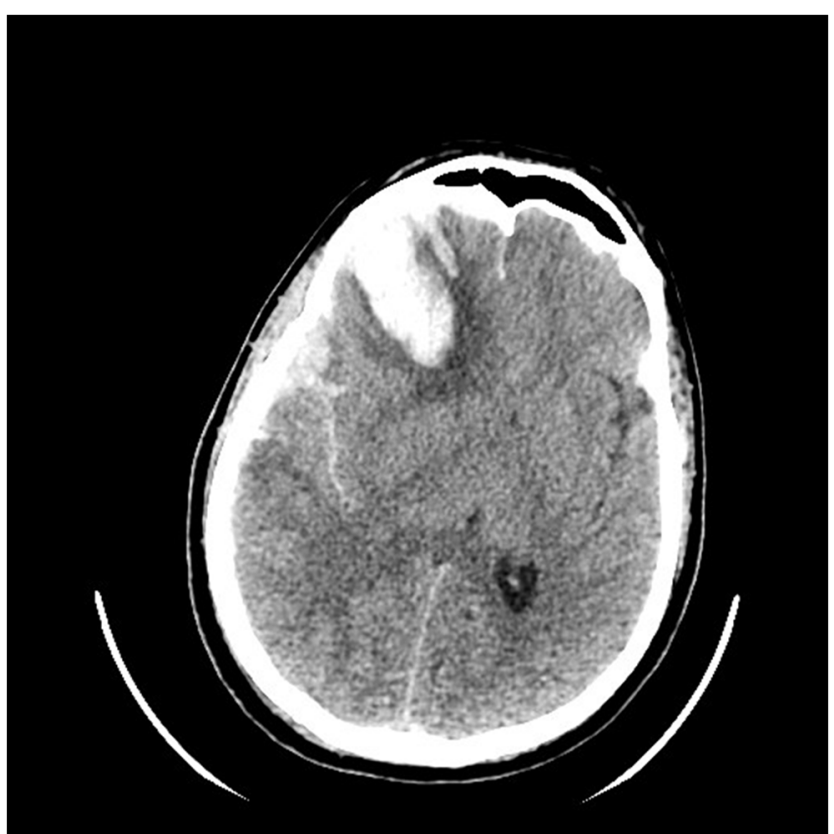

Fig. 1 Non-enhanced CT brain axial cut showing a large parenchymal hematoma in the right frontal lobe with surrounding edema. Extracerebral hemorrhage is also observed subdural as well as subarachnoid. Note the cortical swelling evident as loss of demarcation of gray-white matter interface and effacement of sulci in temporo-occipital region on the right side and frontal lobe on the left

The patient was admitted to the ICU with close neuro-observation. He remained stable and several chest X-rays were all normal.

On May, 2, 2020, the patient was still neurologically stable (GCS 14/15), yet on brain CT follow-up (Fig. 4), the right subdural hematoma had become chronic, and the intracerebral hematoma was re-reabsorbing with persistent perilesional brain edema and midline shift. Based on radiological findings, indication for surgery was advocated; evacuation of the chronic subdural hematoma was performed on $5 / 5$ via burr hole.
The fluid from the chronic subdural hematoma was sent for PCR. Novel coronavirus RNA PCR fluid (CSF) was positive.

\section{Discussion}

Severe acute respiratory syndrome coronavirus (SARS-CoV) is well-known to affect the nervous system and induce polyneuropathy, encephalitis, and aortic ischemic stroke [11, 12]; its presence has been found in CSF [3] and brain parenchyma in autopsies [14].

SARS-CoV has more than $80 \%$ genetic similarity to SARS-Cov2 [4, 8], the virus responsible of COVID-19. Recent clinical data revealed that COVID-19 patients could manifest symptoms such as headache, epilepsy, and disturbed conscious level suggestive of intracranial infections [1, 6]. Others had anosmia and dysgeusia $[2,7,10,15]$. Reports of COVID-19 encephalitis [6] and a case of COVID-19associated acute hemorrhagic necrotizing encephalopathy [7] have been recently published in the medical literature. The presence of coronavirus was found in CSF, hence confirming that the neurological complications observed in these patients are to be attributed to the virus.

Several hypotheses have been advocated to explain neurological complications in COVID-19. Coronavirus is able to bind angiotensin-converting enzyme 2 (ACE2) [2], known to regulate blood pressure and to play an anti-atherosclerosis mechanism; ACE2 is present in the nervous system among other organs. The coronavirus-ACE 2 binding is responsible of direct damage to the blood-brain barrier (BBB); moreover, since on systemic level, it may result in elevating blood pressure, and it predisposes to the occurrence of cerebral hemorrhage.

Another explanation might involve the cytokine cascade. Accumulating evidence has suggested that in a subgroup of patients with severe COVID-19, a secondary hemophagocytic
Fig. 2 a Coronal MIP and $\mathbf{b}$ axial MIP. CTA findings show reduced and somewhat beaded appearance of the distal ICA, A1, and M1 and M2 branches on the right side reflecting vasospasm/vasculitis

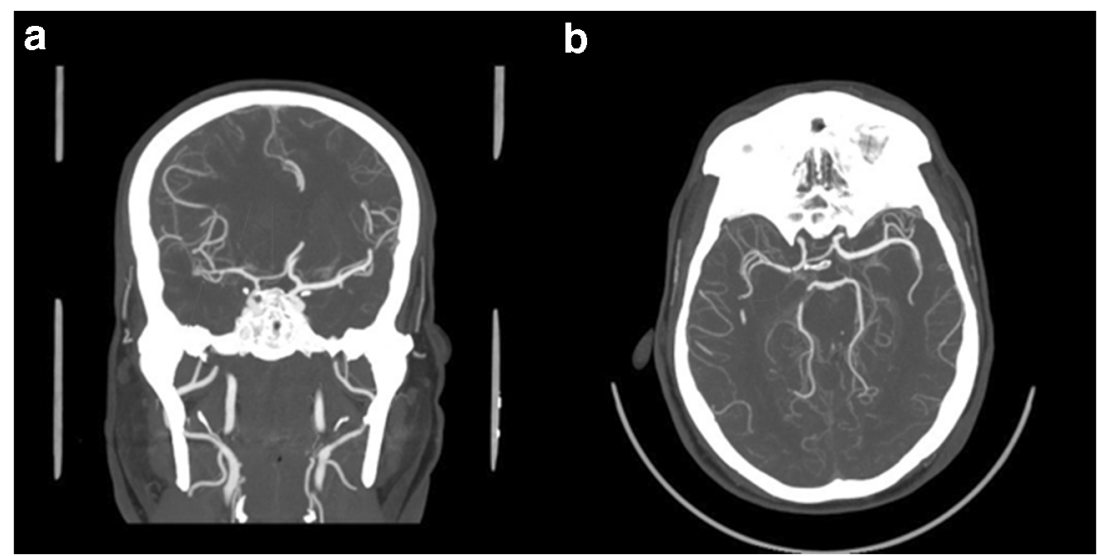


Fig. 3 a and b Delayed postcontrast imaging shows leptomeningeal as well as cortical gyral enhancement supratentorially bilaterally, more pronounced on the right side. The findings strongly suggestive of meningoencephalitis

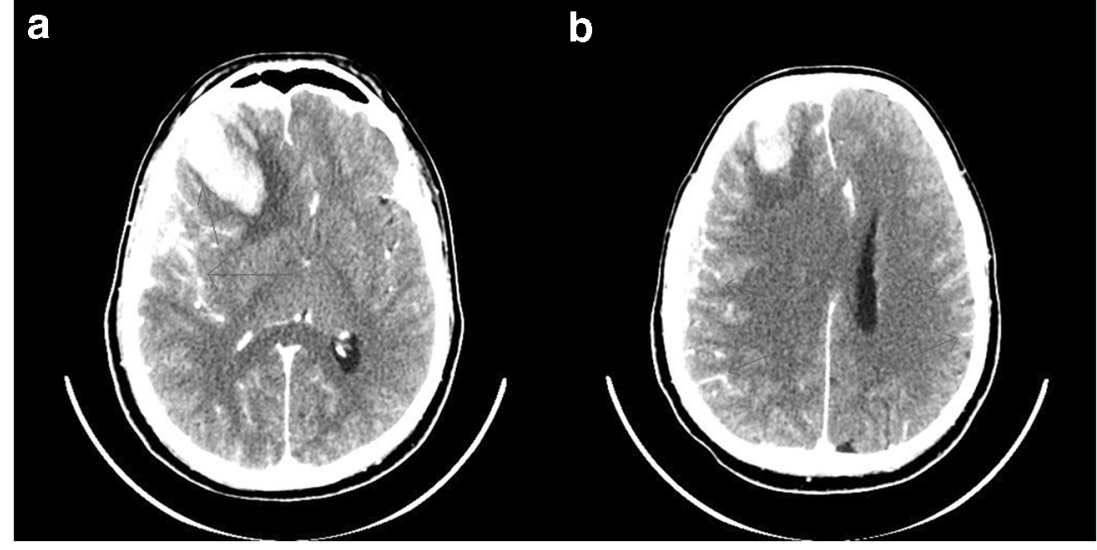

lymphohistiocytosis (sHLH) may develop; this results in a hyperinflammatory syndrome characterized by a fulminant and fatal hypercytokinemia with multiorgan failure [5]. Experimentally, it has been demonstrated that the cytokine cascade could cause intracerebral hemorrhage [7]. COVID19-induced cytokine storm syndrome could be another of the factors behind the occurrence of cerebrovascular events.

The virus seems to have neurotropic properties and may access the CNS through the olfactory nerve; this neuronal pathway is consistent with the clinical observation that some patients with COVID-19 develop anosmia [2, 7, 10, 15].

Our case report gives further evidence of neurological complications in COVID-19. We illustrated the case of a

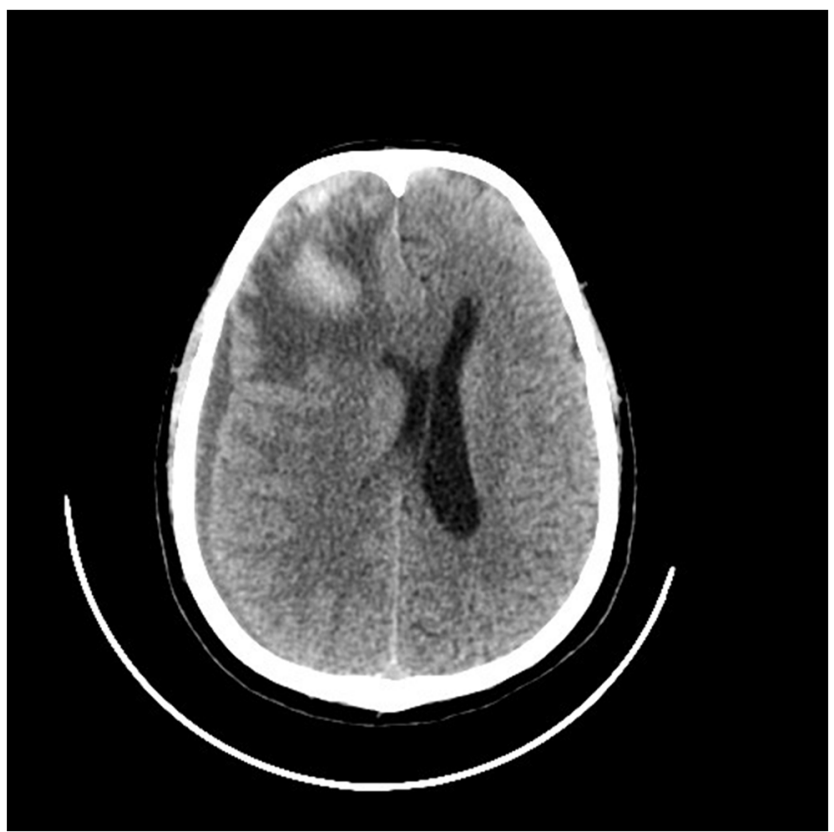

Fig.4 Follow-up imaging shows reduced attenuation of the SDH and good resorption of SAH. The intracerebral hematoma shows signs of partial resorption but mild increase of perifocal edema. No significant interval change of mass effect in the form of effaced sulci and midline shift of about $10 \mathrm{~mm}$ coronavirus-positive 36-year-old patient with unremarkable past medical history that developed a meningoencephalitis with intracerebral and subdural hematomas. On admission, the patient had not been able to report about possible anosmia or dysgeusia due to his state of confusion. Nevertheless, in spite of the contraindication to perform lumbar puncture to detect the presence of the virus in CSF, we had considered the coronavirus infection as the only possible etiology from early diagnostic assessment. Clinical and radiological data were indeed considered suggestive of this etiology; the patient had no history or physical/radiological evidence of head trauma, and imaging had ruled out the possibility of vascular abnormalities and showed findings certainly consistent with viral infection. Later on, our clinical suspicion was eventually confirmed by the analysis of the fluid obtained from the surgical evacuation of the chronic subdural hematoma.

\section{Conclusion}

It has been previously demonstrated that COVID-19 can cause encephalitis and even result in hemorrhagic encephalopathy. Albeit rare, the possibility of neurological complications should be always kept in mind by physicians involved in the diagnosis and management of COVID-19 cases; even in the absence of anosmia/dysgeusia, symptoms like altered conscious level, headache, and sensory-motor deficits should raise a red flag, prompting to investigations that might detect the occurrence of a possible brain damage.

Early diagnosis of encephalomyelitis by imaging is crucial to offer appropriate treatment and prevent evolution towards hemorrhagic encephalopathy, a complication that may cause severe invalidity or even threaten the patient's life.

\section{Compliance with ethical standards}

Conflict of interest The authors declare that they have no conflict of interest. 
Patient consent The IRB board of the (Dubai Health Authority-Dubai Scientific Research Ethics Committee) waived patient consent for this case report submission.

\section{References}

1. Asadi-Pooya AA, Simani L (2020) Central nervous system manifestations of COVID-19: a systematic review. J Neurol Sci 413: 116832. https://doi.org/10.1016/j.jns.2020.116832

2. Baig AM, Khaleeq A, Ali U, Syeda H (2020) Evidence of the COVID-19 virus targeting the CNS: tissue distribution, host-virus interaction, and proposed neurotropic mechanisms. ACS Chem Neurosci 11(7):995-998. https://doi.org/10.1021/acschemneuro. $0 \mathrm{c} 00122$

3. Hung EC, Chim SS, Chan PK, Tong YK, Ng EK, Chiu RW, Leung CB, Sung JJ, Tam JS, Lo YM (2003) Detection of SARS coronavirus RNA in the cerebrospinal fluid of a patient with severe acute respiratory syndrome. Clinical Chemistry. https://oi.org/10.1373/ clinchem.2003.025437

4. Kim JM, Chung Y-S, Jo HJ, Lee NJ, Kim MS, Woo SH, Park S, Kim JW, Kim HM, Han M-G (2020) Identification of coronavirus isolated from a patient in Korea with COVID-19. Osong Public Health Res Perspect 11(1):3-7. https://doi.org/10.24171/j.phrp. 2020.11.1.02

5. Mehta P, McAuley DF, Brown M, Sanchez E, Tattersall RS, Manson JJ (2020) Covid 19: consider cytokine storm syndromes and immunosuppression. Lancet. https://doi.org/10.1016/S01406736(20)30628-0

6. Mingxiang Y, Yi R, Tangfeng L (2020) Encephalitis as a clinical manifestation of COVID-19. Brain Behav Immun. https://doi.org/ 10.1016/j.bbi.2020.04.017

7. Moriguchi T, Harii N, Goto J, Harada D, Sugawara H, Takamino J, Ueno M, Sakata H, Kondo K, Myose N, Nakao A, Takeda M, Haro $\mathrm{H}$, Inoue O, Suzuki-Inoue K, Kubokawa K, Ogihara S, Sasaki T, Kinouchi H, Kojin H, Ito M, Onishi H, Shimizu T, Sasaki Y, Enomoto N, Ishihara H, Furuya S, Yamamoto T, Shimada S
(2020) A first case of meningitis/encephalitis associated with SARS-Coronavirus-2. Int J Infect Dis 94:55-58. https://doi.org/ 10.1016/j.jijid.2020.03.062

8. Mousavizadeh L, Ghasemi S (2020) Genotype and phenotype of COVID-19: their roles in pathogenesis. J Microbiol Imm Inf. https://doi.org/10.1016/j.jmii.2020.03.22

9. Poyiadji N, Shahin G, Noujaim D, Stone M, Patel S (2020) COVID-19-associated acute hemorrhagic necrotizing encephalopathy: CT and MRI features. Radiology:201187. https://doi.org/10. 1148/radiol.2020201187

10. Russell B, Moss C, Rigg A, Hopkins C, Papa S, Van Hemelrijck M (2020) Anosmia and ageusia are emerging as symptoms in patients with COVID-19: what does the current evidence say? Ecancer. https://doi.org/10.3332/ecancer.2020.ed98

11. Tsai L-K, Hsieh S-T, Chang Y-C (2005) Neurological Manifestations in Severe Acute Respiratory Syndrome. Acta Neurol Taiwan 14:113-119

12. Umapathi T, Kor AC, Venketasubramanian N, Lim CCT, Pang BC, Yeo TT, Lee CC, Lim PL, Ponnudurai K, Chuah KL, Tan PH, Tai DYH, Ang SPB (2004) Large artery ischaemic stroke in severe acute respiratory syndrome (SARS). J Neurol 251:1227-1231

13. Wu Y, Xu X, Chen Z, Duan J, Hashimoto K, Yang L, Liu C, Yang C (2020) Nervous system involvement after infection with COVID19 and other coronaviruses. Brain Behav Immun S0889-1591(20): 30357-30353. https://doi.org/10.1016/j.bbi.2020.03.031

14. Xu J, Zhong S, Liu J, Li L, Li Y, Wu X, Li Z, Zhang J, Zhong N, Ding Y, Jiang Y (2005) Detection of severe acute respiratory syndrome coronavirus in the brain: potential role of the chemokine Mig in pathogenesis. Clin Infect Dis 41(8):1089-1096. https://doi.org/ $10.1086 / 444461$

15. Xydakis MS, Dehgani-Mobaraki P, Holbrook EH, Geisthoff UW, Bauer C, Hautefort C, Herman P, Manley GT, Hopkins C (2020) Smell and taste dysfunction in patients with COVID 19. Lancet Infect Dis. https://doi.org/10.1016/s1473-3099(20) 30293-0

Publisher's note Springer Nature remains neutral with regard to jurisdictional claims in published maps and institutional affiliations. 